\title{
EXPERIMENTAL STUDY ON THREE STOREY BUILDING FRAME MODEL
}

\author{
Mr. Kavan M.R. \\ Assistant Professor, \\ Department of Civil Engineering \\ Adichunchanagiri Institute of Technology, \\ Chikkamagaluru, Karnataka, India
}

\author{
Mr. Arjun A.B. \\ Assistant Professor, \\ Department of Civil Engineering \\ Adichunchanagiri Institute of Technology \\ Chikkamagaluru, Karnataka, India
}

\author{
Mr. Theju R.K. \\ M.Tech Student, \\ Department of Civil Engineering \\ Adichunchanagiri Institute of Technology, \\ Chikkamagaluru, Karnataka, India
}

\begin{abstract}
Experimental investigations were conducted on a three storey building frame model comprising of columns and slabs, where the frame is rectangular in plan with stiffness and mass properties distributed uniformly in plan as well as in elevation. Also, the frame is designed to facilitate the visualization of the first three mode shapes with bare eyes. The base of the building frame was subjected to harmonic motion using horizontal shake table. This experiment also enables the understanding the occurrence of resonance phenomenon in simple multidegree of freedom (MDOF) systems. The frequency of the base motion can be varied by changing the RPM of the electric motor; it is also possible to vary the amplitude. The natural frequencies and mode shapes were obtained. The same building frame was analyzed using ETABS 2015 for both natural frequencies and mode shapes. The experimental and analytical values of natural frequencies obtained were compared where the analytical values obtained from the ETABS 2015 were found closer to the experimental values.
\end{abstract}

\section{Keywords - Natural frequency, Mode Shapes, Horizontal shake table}

\section{INTRODUCTION}

Several sizeable earthquakes have caused severe damage in civil structures all over the world. To protect civil structures from significant damage, the response reduction of civil structures under such severe earthquakes has become an important topic in structural engineering. Therefore study of the response of structure is very important [1]. Recently it has become mandatory to design all the civil engineering structures including load effects. The determination of natural frequencies and mode shapes is of vital importance in the dynamic analysis of structures [2].

Shake table is a mechanical device that is used to produce simple harmonic excitation by which response of a structure is obtained. It is very important for the engineers while designing a structure that the resonant frequencies of the component part do not match with the oscillating frequency of the vibratory parts as it may cause violent swaying motions thereby leading to catastrophic disasters and failure of structure. So, in order to check this resonant frequency shake tables can be used [3]. A few of the dynamic studies made by earlier research workers are briefly mentioned here. C. G. Konapure et.al (2018) [4] has studied the seismic performance of multistory building to identify the most influential structural parameters. The dynamic property such as time period of multistory building is determined analytically and experimentally. The analytical results are compared with experimental results. The effect of experimental results (time period) on dynamic property and design of building elements also evaluated. Rafiqul Islam et.al (2018) [5] has studied Structural properties (damping ratio, stiffness, natural frequency, natural period, mode shape) of a three-story model frame and its deflection behavior under repetitive strong shaking is investigated through shaking table tests. Further effectiveness of various bracing system under multidirectional seismic excitation is analytically investigated.

In the present work a shake table test is performed on a threestoried building frame and the natural frequencies and mode shapes are determined. These experimental results are compared with the ETABS 2015. 


\section{EXPERIMENTAL METHOD}

\section{A. Investigational model -}

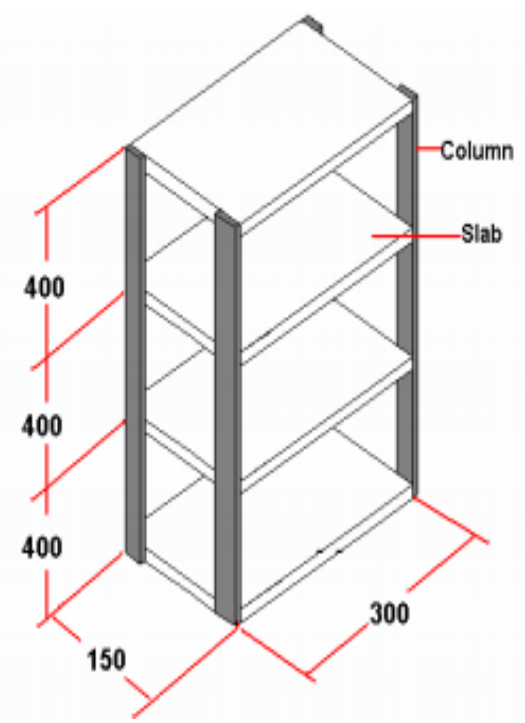

Fig. 1. Schematic Diagram of Three-Story frame

Table - 1 Geometric Data of the Structure

\begin{tabular}{|c|c|c|c|c|}
\hline Sl. No & \multirow{2}{*}{ Part } & \multicolumn{3}{|c|}{ Dimension in mm } \\
\cline { 3 - 5 } & & Depth & Width & Length \\
\hline 1 & Column & 3 & 25 & 400 \\
\hline 2 & Slab & 6 & 150 & 300 \\
\hline
\end{tabular}

The test building model is a regular three-storied rectangular model made up of steel. The modulus of elasticity and Poisson ratio of steel are $210 \mathrm{GPa}$ and 0.3 respectively. The material of the model is a linear elastic isotropic material with a density of $7850 \mathrm{~kg} / \mathrm{m} 3$.

\section{B. Experimental procedure -}

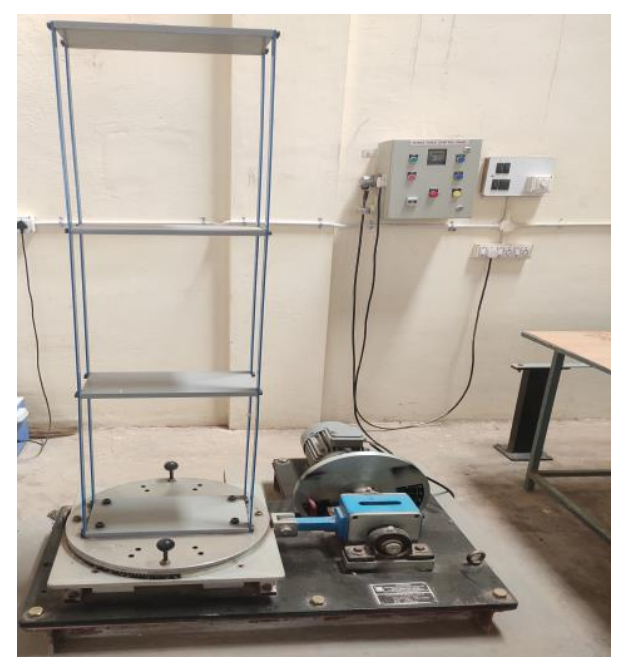

Fig. 2. Experimental Model mounted on a Horizontal Shake Table

The procedure is as follows:

Part 1: Initial setting of amplitude

- Using an allen key slack the grub screw which is on outer cam.

- Allen key is then placed in the grub screw which is pointed out with red shading.

- Flywheel is then revolved in counter-clockwise direction by holding the allen key till the allen key contacts plate of the interfacing pole, which is set apart with red shading.

- Slacken the red hued grub screw without troubling the situation of the allen key.

- Rotate the flywheel in counter-clockwise direction to modify the amplitude with the help of red pointer.

- Adjust the flywheel at any ideal amplitude concerning the pointer, let us state "1" and fix the red shaded grub screw without upsetting the allen key position and afterward fix another grub screw which is set inverse to the red hued grub screw.

- Presently fix appropriately two grub screws to the most extreme.

Part 2: Fixing the model and experiment conduction

- Now place the experimental model on the rotating table and tighten the mounting bolts of the model.

- Fix 4 accelerometers at bottom similarly at every floor levels so that dislocation along $\mathrm{x}$-direction can be gotten. At that point interface the USB link from MILDAQ System to Computer/Laptop.

- Turn ON the mains and the MCB. Press the "RUN/START" button on the control board. A little red pointer inside the drive will sparkle and the showcase will show "0.00".

- For a given engine RPM (Frequency), permit the frame to oscillate for a couple of moments with the goal that the frame arrives at its firm position. At this phase record data from the software comparing dislocation values for every floor. Recognize the frequencies at which the structure experiences reverberation by watching the variety of reaction amplitudes. At reverberation of the model, record the natural frequency and comparing displacement data.

- When examination is completed press the "RESET" button on control board which will carry back the frequency to zero. Put off the MCB.

\section{Experimental results}




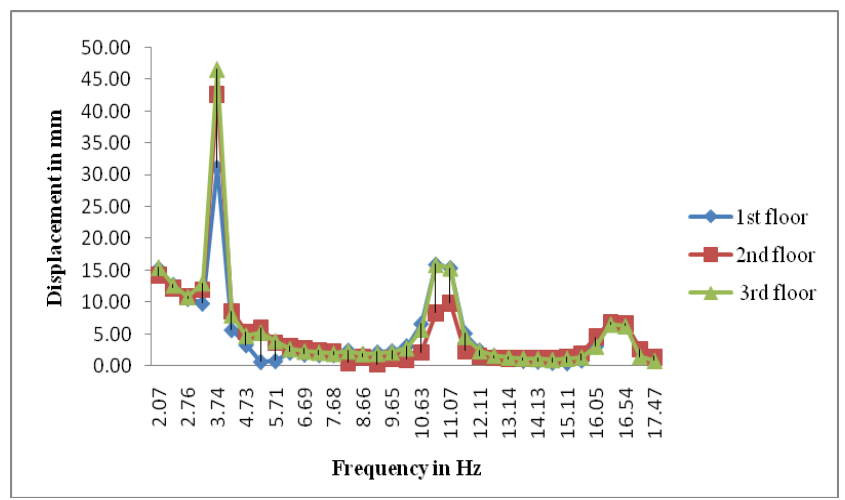

Fig. 3. Graph of Displacement of Floors for 1mm Amplitude

Fig.3. exhibits the graph of displacement of floors for the amplitude of $1 \mathrm{~mm}$, as the frequency increases the values of displacement in the different floors will be decreasing and there will be slight increase in the displacement of the floors at the natural frequencies.

The 3 natural frequencies gained are,

$\mathrm{f}_{1}=3.74 \mathrm{~Hz}, \mathrm{f}_{2}=10.88 \mathrm{~Hz}$ and $\mathrm{f}_{3}=16.29 \mathrm{~Hz}$

The natural time period with respect to natural frequencies are,

$\mathrm{T}_{\mathrm{n} 1}=0.267 \mathrm{sec}, \mathrm{T}_{\mathrm{n} 2}=0.091 \mathrm{sec}$ and $\mathrm{T}_{\mathrm{n} 3}=0.061 \mathrm{sec}$

Table - 2 Deformed Pattern

\begin{tabular}{|c|c|c|c|}
\hline & $1^{\text {st }}$ mode shape & $2^{\text {nd }}$ mode shape & $3^{\text {rd }}$ mode shape \\
\hline $1^{\text {st }}$ floor & 1 & 1 & 1 \\
\hline $2^{\text {nd }}$ floor & 1.37 & 0.52 & -1.01 \\
\hline $3^{\text {rd }}$ floor & 1.49 & -0.99 & 0.96 \\
\hline
\end{tabular}

\section{ANALYTICAL METHOD}

\section{A. Methodology -}

ETABS is an ultimate integrated software package for the structural analysis and design of buildings where it is utilized to carry out limited component examination. Modeling type of shell-thin component is utilized for the element of slab. Similarly for the column element beam component is utilized. The column and slab of the structure outline model are demonstrated as portrayed previously. The support is compelled in every direction and the modular examination is finished utilizing eigen-value framework technique [2]. The examination model is appeared in Fig.4.

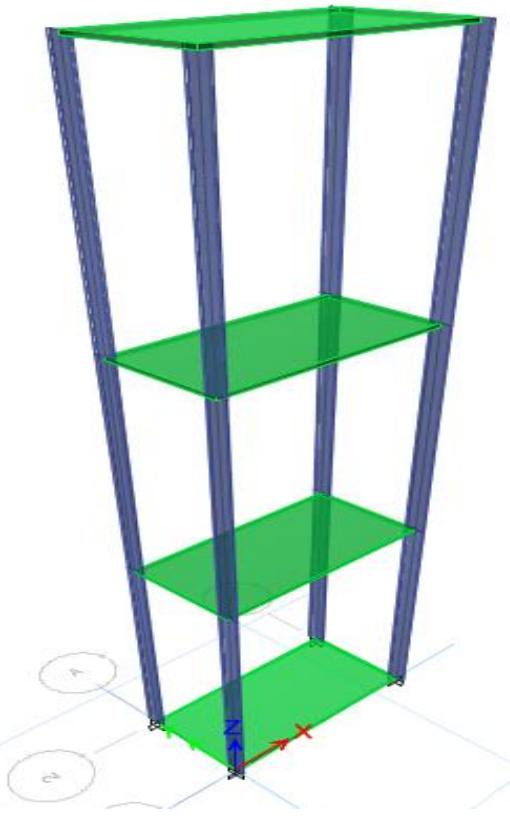

Fig. 4. ETABS Model for Analysis

\section{B. Analytical results -}

For 3 storey building frame without bracing,

The 3 natural frequencies gained from ETABS are, $\mathrm{f}_{1}=3.90 \mathrm{~Hz}, \mathrm{f}_{2}=10.86 \mathrm{~Hz}$ and $\mathrm{f}_{3}=15.52 \mathrm{~Hz}$

The natural time period with respect to natural frequencies are,

$$
\mathrm{T}_{\mathrm{n} 1}=0.256 \mathrm{sec}, \mathrm{T}_{\mathrm{n} 2}=0.092 \mathrm{sec} \text { and } \mathrm{T}_{\mathrm{n} 2}=0.064 \mathrm{sec}
$$

Table - 3 Deformed Pattern

\begin{tabular}{|c|c|c|c|}
\hline & $1^{\text {st }}$ mode shape & $2^{\text {nd }}$ mode shape & $3^{\text {rd }}$ mode shape \\
\hline $1^{\text {st }}$ floor & 1 & 1 & 1 \\
\hline $2^{\text {nd }}$ floor & 1.8 & 0.36 & -1.29 \\
\hline $3^{\text {rd }}$ floor & 2.22 & -0.88 & 0.71 \\
\hline
\end{tabular}




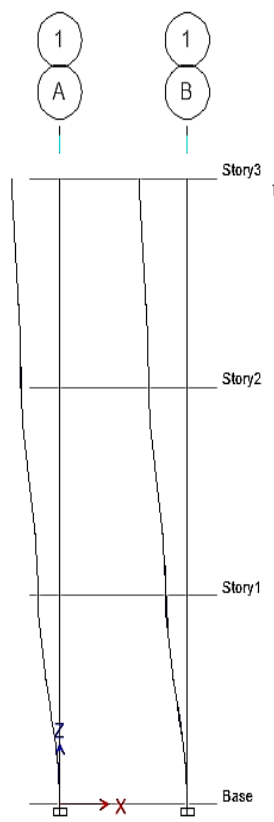

( a)

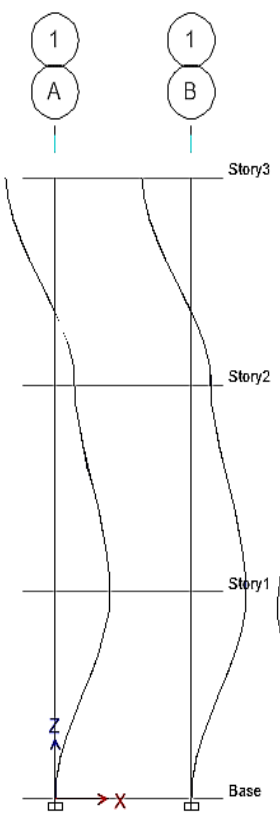

(b)

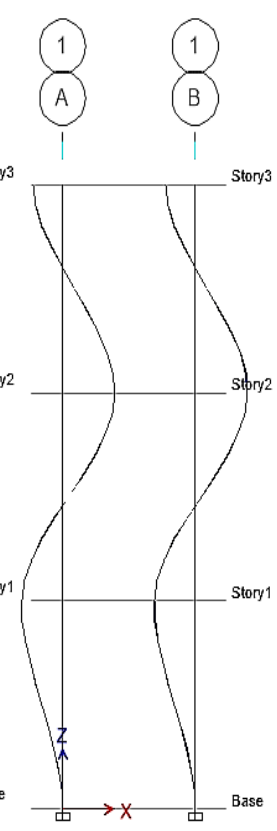

(c)
Fig. 5. (a) First mode shape (b) Second mode shape (c) Third mode shape

\section{RESULTS AND DISCUSSION}

Table - 4 Comparison of Natural Frequencies

\begin{tabular}{|c|c|c|}
\hline \multirow{2}{*}{} & \multicolumn{2}{|c|}{ Natural frequencies in $\mathrm{Hz}$} \\
\cline { 2 - 3 } & Experimental & Analytical \\
\hline $1^{\text {st }}$ mode & 3.74 & $3.90(4.35 \%)$ \\
\hline $2^{\text {nd }}$ mode & 10.88 & $10.86(0.15 \%)$ \\
\hline $3^{\text {rd }}$ mode & 16.29 & $15.52(4.70 \%)$ \\
\hline
\end{tabular}

Note: The percentage of error relative to experimental value is mentioned within parentheses

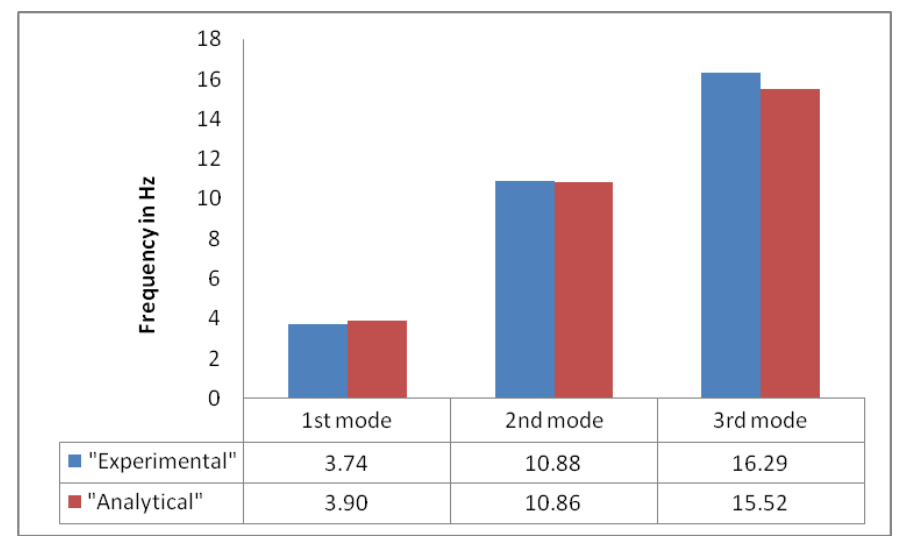

Fig. 6. Graph of Natural Frequency versus Mode
Fig.6. exhibits the graph of natural frequency comparison between experimental and analytical results.

\section{CONCLUSION}

- $\quad$ For three storey building frame model experiment has been conducted for an $1 \mathrm{~mm}$ amplitude. Which shows that as the frequency increases the displacement of floors reduces. For that the natural frequency, natural time period and mode shapes were gained.

- From software ETABS the natural frequencies, natural time period and mode shapes were obtained for a model. Comparatively the results obtained are faster hence it is time saving.

- The experimental and analytical values of natural frequencies obtained were compared where the analytical values obtained from the ETABS 2015 were found close enough to the experimental values.

\section{REFERENCE}

[1] C.S. Sanghvi, H.S. Patil and B.J. Shah, "Experimental study of dynamic response of soft storey building model", International Journal of Advanced Engineering Research and Studies, vol. I Issue I, pp. 192-197, 2011.

[2] Supreeth A.R., Rekha B., Prema Kumar W.P., and Shijina K., "Experimental and Numerical Studies on Free Vibration Characteristics of a Three-Storied Building Frame" Published in IRJET, Vol.4 Issue 05, pp. 241-245, 2015.

[3] Md Mohsin M Dafedar, "Low Cost Uniaxial Shake Table for Harmonic Excitation" Published in IRJET, Vol.06 Issue 06, pp. 1287-1293, 2019.

[4] C.G. Konapure and M.S. Muddiddi, "Determination of time period and evaluation of seismic response of framed structure with different approaches", Published in IRJET Vol.05 Issue04, pp. 955-960, 2018.

[5] Rafiqul Islam, Md. Tarek Hossain, Md. Jahir Bin Alam and Mushtaq Ahmed, "Study of Dynamic Behavior of a Three Story Model Frame", American Journal of Construction and Building Materials, Vol. 2, No. 1, pp. 10-15, 2018.

[6] Supriya Mali and D.B Kulkarni, "Experimental Parametric Study of Diagrid Structure under Seismic Forces", Published in IRJET, Vol. 06 Issue 04, pp. 42254230, 2019.

[7] A.P. Kulkarni, M.K. Sawant and M.S. Shinde Patil, "Experimental study using earthquake shake table", Published in American Journal of Construction and Building Materials, Vol. 04 Issue 04, pp. 3612-3617, 2017. 
[8] A.N. Swaminathen and P. Sankari, "Experimental Analysis of Earthquake Shake Table" Published in American Journal of Engineering Research (AJER), Vol. 6 Issue 1, pp. 148-151, 2017.

[9] Anurag Sharma, Chintan Pathek and Mohd Nasim, "Characterization and application of shake table for structural model testing" Published in International journal of engineering sciences \& research technology, pp. 48-54, 2015.

[10] Neha Tirkey and G.B. Ramesh Kumar, "Experimental on the residential building of earthquake prone areas using shake table test", Published in IJITEE, Vol. 8 Issue 6S4, pp. 260-263,April 2019.

[11] Cinitha A., Umesha. P.K. and Nagesh. R. Iyer, "A Rational Approach for Fundamental Period of Low and Medium Rise Steel Building Frames", International Journal of Modern Engineering Research (IJMER), vol. 2 Issue 5, pp-3340-3346, 2012.

[12] Seug-Eock kim, "Shaking table test of a two-story unbraced steel frame", journal of construction steel research, 2005.

[13] P.G. Carydis, H.P. Mouzakis and E.A. Vougioukas, "Comparative assessment of shaking tables", Eleventh world conference on earthquake engineering, 1996.

[14] J.S Hwang, K.C. Chang and G.C. Lee, "The system characteristics and performance of a shaking table", National conference on earthquake engineering research, 1987.

[15] M. Paz, "Structural dynamics", CBS Publishers, New Delhi, 1984. 